The mean age at diagnosis was 45,01 years (SD 16,71 \pm years), The median of tracing was seven yeas (P25 de four years/P75 de 14 years). The mean initial antiRNP titre was 239,33 the median was 144 (P25 58/P75 400). The initial diagnosis were Mixed Connective Tissue Disease 6,25\% (4), Undifferentiated Connective Tissue Disease $31,25 \%$ (20), systemic erythematosus lupus $45,31 \%$ (29) and Others $14,06 \%$ (9). MCTD diagnosis was made in $29,69 \%$ (19) of patients at the end of follow-up. Patients with MCTD as final diagnosis presented in their first visit Raynaud phenomenon $73,68 \%$ (14), puffy hands $31,58 \%(5)$, acrosclerosis $10,56 \%$ (2), myositis $21,05 \%$ (4), Arthralgias $68,42 \%$ (13), arthritis $57,89 \%$ (11), Pulmonary arterial hypertension $5,26 \%$ and Interstitial lung disease $10,53 \%$ (2). The initial RNP titre was evaluated using the number of times over the laboratory cut point. The area under the ROC curve for the initial RNP was 0,70 . Looking for the highest specificity with and adequate sensitivity, we selected the cut-point with highest LR + . The selected cut-point was $\geq 24,4$ times the laboratory cut-point, with s specificity of 77,78 and a sensitivity of 57,89 .

Conclusions: The cut-point for low/high RNP titres measured by ELISA in our cohort of patients with MCTD as a final diagnosis was $\geq 24,4$ times the laboratory cut-point.

References:

[1] Sharp GC, Irvin WS, Tan EM, Gould RG, Holman HR. Mixed connective tissue disease-an apparently distinct rheumatic disease syndrome associated with a specific antibody to an extractable nuclear antigen (ENA). Am J Med. 1972 Feb;52(2):148-59.

[2] Amigues JM1, Cantagrel A, Abbal M, Mazieres B. Comparative study of 4 diagnosis criteria sets for mixed connective tissue disease in patients with anti-RNP antibodies. Autoimmunity Group of the Hospitals of Toulouse. J Rheumatol. 1996 Dec;23(12):2055-62.

Disclosure of Interest: None declared

DOI: 10.1136/annrheumdis-2017-eular.6914

\section{AB0978 ASSOCIATION OF INFLAMMATORY ARTHRITIS WITH VOGT-KOYANAGI-HARADA SYNDROME (VKHS)}

D. Ramos-Bello ${ }^{1}$, G. Aguilera Barragán-Pickens ${ }^{1}$, A.J. Pedro-Martínez ${ }^{1}$, G. Martínez-Flores ${ }^{1}$, T.A. Luna-Zúñiga ${ }^{1}$, A.N. Rangel-Botello ${ }^{1}$,

P.L.R. Hernández-Briano ${ }^{2}$, M.G. Rangel-Charqueño ${ }^{2}$, E. Santillán-Guerrero ${ }^{1}$,

C. Abud-Mendoza ${ }^{1} .{ }^{1}$ Unidad regional de Reumatología y Osteoporosis;

2 Departamento de Oftalmología, Hospital Central "Dr. Ignacio Morones Prieto" y Facultad de Medicina de la Uaslp, SLP, Mexico

Background: VKHS is a rare cause of granulomatous uveitis leading to significant visual loss in patients who develop it, usually accompanied with extraocular manifestations that include meningismus, vitiligo, poliosis, and hearing loss. In our country is responsible for $13 \%$ to $27 \%$ of all uveitis, affecting mainly young women.

Objectives: To describe the presence of inflammatory arthritis in patients with VKHS at a third level hospital.

Methods: A cross-sectional study of 4 patients with established VKHS that fulfilled the 2001 revised diagnostic criteria for Vogt-Koyanagi-Harada disease (1) was rolled out. Ultrasonography was performed to all patients by a trained rheumatologist in carpal, metacarpophalangeal (MCP) and proximal interphalangeal (PIP) joints evaluating presence of power Doppler (PD) signal, bone erosions, and cartilage changes.

Results: We included 3 women and 1 man, mean age was $34.7 \pm 10.3$ years, and they all had characteristics of complete VKHS. Mean disease duration (since first manifestation of ocular symptoms) was $5.2 \pm 3.5$ months. One patient had synovitis on physical examination. Out of the 4 patients with PD signal, 4 had involvement of both wrist, MCP and PIP joints consistent with polyarthritis pattern, and bone erosions were detected in one patient (Table)

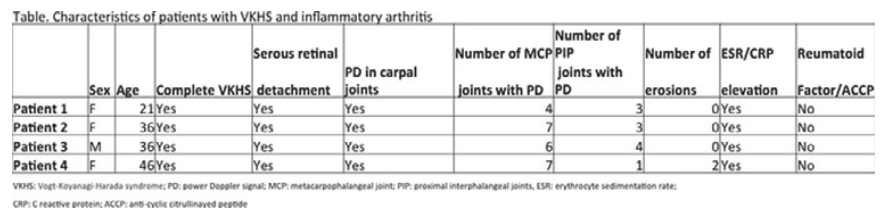

Conclusions: The presence of inflammatory arthritis in patients with VKHS has only been described in one case (2). Despite the exceptionality, we propose that polyarthritis and probably erosive arthritis can represent part of the spectrum of the disease, processes that share some features of the genetic susceptibility with rheumatoid arthritis as HLA-DR4, CTLA-4 and STAT4.

\section{References:}

[1] Read RW, et al. Revised diagnostic criteria for Vogt- Koyanagi-Harada disease: report of an international committee on nomenclature. Am J Ophthalmol 2001; 131:647-652.

[2] Aydin T, et al. Association of Vogt Koyanagi Harada Syndrome and Seronegative Rheumatoid Arthritis. Ethiopian Journal of Health Sciences. 2016;26(2):193-196.

Disclosure of Interest: None declared

DOI: 10.1136/annrheumdis-2017-eular.4483

\section{AB0979 EOSINOPHILIC FASCITIS: CLINICAL EXPERIENCE IN A SERIES OF 21 PATIENTS}

J.C. Quevedo ${ }^{1}$, R. Lopez ${ }^{1}$, M. Garcia-Bustuinduy ${ }^{2}$, C. Rodriguez-Lozano ${ }^{1}$,

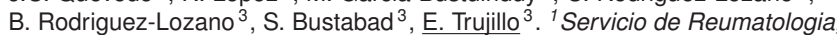
Hospital Universitario de Gran Canaria Doctor Negrin, Las Palmas; ${ }^{2}$ Servicio de Dermatologia; ${ }^{3}$ Servicio de Reumatologia, Hospital Universitario de Canarias, la Laguna, Spain

Background: The Eosinophilic fascitis (EF) is a uncommon sclerodermiforme síndrome with unknown etiology and poorly understood pathogenesis and natural evolution. The published series are short, with a total of 280 cases described in the literature from 1974

There is neither clinical tests nor consensus on the EF treatment.

Objectives: To describe a series of 21 patients with EF.

Methods: Multicentric, retrospective Case Series Study.

We reviewed 21 patients diagnosed of EF (cutaneous induration+consistent biopsy) between January 1998 to January 2015. A total of 13 males and 8 females.

Results: The mean age at diagnosis was 41 years 8 range between 28 and 66). Trigger factor was suspected in 8 patients (intense exercise in 7).

The zones of cutaneous affectation were fundamentally the upper and low extremities.

The hyperesonophilia was present in $100 \%$ of the patients. The average of the $\%$ more high of hyperesosinophilia was $21.2 \%$ (range $4-45.4 \%$ ).

11 patients presented artralgias and 5 patients presented arthritis ( 4 polyarticular/1 oligoarticular).

The MRI was used for diagnosis and/or follow-up in 8 patients, especially in the diagnosed ones in the last 5 years.

The average initial dose of prednisone was $40 \mathrm{mg} / \mathrm{día}$, the average maximum dose of prednisone was $40 \mathrm{mg} / \mathrm{dia}$ and the mean steroid treatment duration was 22 months (range 9-47 months). Other immunomodulatory agents were: methotrexate 11 , hydroxychloroquine 2 , azatioprina 2 and $\mathrm{D}$ penicillamine 1 .

5 years after follow-up, the evolution was the complete resolution in 13 patients and the partial improvement in 6 .

\begin{tabular}{lcc}
\hline Other clinical and analytical manifestations (N=21). & YES, $\mathrm{n}(\%)$ & $\mathrm{NO}, \mathrm{n}(\%)$ \\
\hline Hypergammaglobulinemia & $13(63)$ & $8(37)$ \\
Elevated ESR & $4(16)$ & $17(84)$ \\
Elevated CRP & $8(37)$ & $13(63)$ \\
Elevated CK & 0 & $21(100)$ \\
Systemic symptoms & $7(32)$ & $14(68)$ \\
Visceral affectation & $3(11)$ & $18(89)$ \\
Autoimmune thyroid & $2(5)$ & $19(95)$ \\
Peripheral neuropathy & $4(16)$ & $17(84)$ \\
\hline
\end{tabular}

Conclusions: In our series, the EF prevails in males, in the decade of the 40 and in the majority one did not find trigger factor. There was presence of arthritis in a significant percentage of patients. In the last years the use of the RMN has been added to the diagnosis and to the follow-up. Though there are no clinical tests that support it the use of the metotrexato has been generalized as adjuvant treatment to the steroids.

Disclosure of Interest: None declared

DOI: 10.1136/annrheumdis-2017-eular.6444

\section{AB0980 EPIDEMIOLOGICAL PROFILE OF THE PULMONARY DISEASES IN MIXED CONNECTIVE TISSUE DISEASE: ABOUT 55 CASES}

R. Amri ${ }^{1}$, I. Mejri ${ }^{1}$, H. Sahli ${ }^{2}$, A. Mahfoudhi ${ }^{1}$, I. Ben Ahmed ${ }^{1}$, R. Jazi ${ }^{1} .{ }^{1}$ Internal Departement; ${ }^{2}$ Rheumatology Departement, Mohamed Taher Maamouri University Hospital, nabeul, Tunisia

Background: Mixed connective tissue disease (MCTD) are a systematic autoimmune disease that the aetiopathogeny remains misunderstood. This disease is often associated with systemic involvement which sometimes is very serious, such as pulmonary diseases.

Objectives: To describe the characteristics of the pulmonary diseases among a sample of MCTD.

Methods: We conducted a retrospective study including patient's cases diagnosed with a MCTD between the period of 10 years in the departement of internal medicine. The demographic, clinical, treated in the immunological, biological and radiological data were collected then analysed.

Results: In total we had 55 patients. $87 \%$ of them were female. The mean age of the sample was $50,64 \pm 15$ years. Major types of MCTD were: Rheumatoid polyarthritis $(45.5 \%)$, sarcoidosis $(18.2 \%)$, scleroderma $(12.7 \%)$, and the lupus erythematosus $(10.9 \%)$. These causes were diagnosed after a mean delay of 686, 18 days. A lung disease was found in $50.9 \%$ of the cases. It was either present without symptoms in $52.8 \%$ of the cases or revealed by dyspnoea $(22.6 \%)$, a cough (18.9\%)or hemoptysie isolated or associated to thoracic pains $(1.9 \%$ each).The most frequent type of respiratory diseases were adenopathies (26.9\%). Pleurisy, fibrosis, and interstitial lung diseases were described among $11.5 \%$ of the cases. Bronchiectasis, Lung arterial high blood pressure, pleural nodules, bronchi dilatation were reported in $7.7 \%$. In only $3.8 \%$ we had patients with cancer and emphysema. Chest radiographs were normal in $65.5 \%$ of the 